\title{
Seed characterization and early nitrogen metabolism performance of seedlings from Altiplano and coastal ecotypes of Quinoa
}

Katherine Pinto-Irish ${ }^{1}$, Teodoro Coba de la Peña ${ }^{1}$, Enrique Ostria-Gallardo ${ }^{1}$, Cristian Ibáñez ${ }^{2}$, Villbett Briones ${ }^{3}$, Alexander Vergara ${ }^{4}$, Rodrigo Alvarez ${ }^{1,5}$, Catalina Castro ${ }^{6}$, Carolina Sanhueza ${ }^{6}$, Patricio A. Castro ${ }^{7 *}$ and Luisa Bascuñán-Godoy ${ }^{1,6^{*}}$

\begin{abstract}
Background: Early seed germination and a functional root system development during establishment are crucial attributes contributing to nutrient competence under marginal nutrient soil conditions. Chenopodium quinoa Willd (Chenopodiaceae) is a rustic crop, able to grow in marginal areas. Altiplano and Coastal/Lowlands are two representative zones of quinoa cultivation in South America with contrasting soil fertility and edaphoclimatic conditions.

In the present work, we hypothesize that the ecotypes of Quinoa from Altiplano (landrace Socaire) and from Coastal/Lowland (landrace Faro) have developed differential adaptive responses in order to survive under conditions of low availability of $\mathrm{N}$ in their respective climatic zones of Altiplano and Lowlands. In order to understand intrinsic differences for $\mathrm{N}$ competence between landraces, seed metabolite profile and germinative capacity were studied. Additionally, in order to elucidate the mechanisms of $\mathrm{N}$ uptake and assimilation at limiting $\mathrm{N}$ conditions during establishment, germinated seeds of both landraces were grown at either sufficient nitrate (HN) or low nitrate (LN) supply. We studied the photosynthetic performance, protein storage, root morphometrical parameters, activity and expression of $\mathrm{N}$-assimilating enzymes, and the expression of nitrate transporters of roots in plants submitted to the different treatments.

(Continued on next page)
\end{abstract}

\footnotetext{
* Correspondence: pacastro@udec.cl; lubascun@udec.cl

${ }^{1}$ Centro de Estudios Avanzados en Zonas Áridas (CEAZA), 1710088 La Serena,

Chile

'Laboratorio de Fisiología Vegetal, Departamento de Botánica, Facultad de

Ciencias Naturales y Oceanográficas, Universidad de Concepción, Casilla

160-C, 4070386 Concepción, Chile

${ }^{7}$ Departamento de Fisiología, Facultad de Ciencias Biológicas, Universidad de Concepción, 4070386 Concepción, Chile

Full list of author information is available at the end of the article
}

(c) The Author(s). 2020 Open Access This article is licensed under a Creative Commons Attribution 4.0 International License, which permits use, sharing, adaptation, distribution and reproduction in any medium or format, as long as you give appropriate credit to the original author(s) and the source, provide a link to the Creative Commons licence, and indicate if changes were made. The images or other third party material in this article are included in the article's Creative Commons licence, unless indicated otherwise in a credit line to the material. If material is not included in the article's Creative Commons licence and your intended use is not permitted by statutory regulation or exceeds the permitted use, you will need to obtain permission directly from the copyright holder. To view a copy of this licence, visit http://creativecommons.org/licenses/by/4.0/. The Creative Commons Public Domain Dedication waiver (http://creativecommons.org/publicdomain/zero/1.0/) applies to the data made available in this article, unless otherwise stated in a credit line to the data. 


\begin{abstract}
(Continued from previous page)
Results: Seeds from Socaire landrace presented higher content of free N-related metabolites and faster seed germination rate compared to Faro landrace. Seedlings of both ecotypes presented similar physiological performance at HN supply, but at LN supply their differences were exalted. At LN, Socaire plants showed an increased root biomass (including a higher number and total length of lateral roots), a differential regulation of a nitrate transporter (a NPF6.3-like homologue) belonging to the Low Affinity Transport System (LATS), and an upregulation of a nitrate transporter (a NRT2.1-like homologue) belonging to the High Affinity nitrate Transport System (HATS) compared to Faro. These responses as a whole could be linked to a higher amount of stored proteins in leaves, associated to an enhanced photochemical performance in Altiplano plants, in comparison to Lowland quinoa plants.
\end{abstract}

Conclusions: These differential characteristics of Socaire over Faro plants could involve an adaptation to enhanced nitrate uptake under the brutal unfavorable climate conditions of Altiplano.

Keywords: Nitrogen metabolism, N transport, Glutamine synthetase, Photochemical process, Chlorophyll fluorescence, Nitrate reductase, Nitrate transporters, Nitrate-sensing, Proteins, Crop yield

\section{Background}

Nitrogen is a nutrient of foremost importance to predict physiological performance and yield of plants [1]. Nitrogen $(\mathrm{N})$ is a component of many macromolecules including nucleic acids and proteins. Plant $\mathrm{N}$ compounds also include components of the ornithine cycle and the shikimate pathway [2].

Nitrogen stored in seeds has an important ecological role because it is involved in seed predation, protection and germination [3, 4]. Furthermore, it was suggested that metabolites stored in seeds represent a defined metabolic status and they may play a regulatory role over gene expression, defining levels of dormancy or/ and ripening [5, 6]. Additionally, metabolites in seeds play a major role in early performance of species under poor nutrient conditions [7, 8].

After germination, the ability of seedlings for $\mathrm{N}$ uptake and assimilation from soils depends on various factors including, available form of $\mathrm{N}$, presence of other nutrients, soil characteristics, $\mathrm{pH}$, temperature, abiotic factors, biotic interactions, competition, root structure, etc. In most plant species, only a small proportion of soil $\mathrm{N}$ is taken up and assimilated by plant roots. Plant can capture different inorganic forms of $\mathrm{N}$ in the roots, but nitrate $\left(\mathrm{NO}_{3}{ }^{-}\right)$is the major $\mathrm{N}$ source absorbed and assimilated by plants in aerobic soils [9]. Nitrate reductase (NR) catalyzes the first reaction in nitrate assimilation, the reduction of nitrate to nitrite. Nitrite reduction to ammonium is catalyzed by the enzyme nitrite reductase (NiR). Then, glutamine synthetase (GS) incorporates ammonium into glutamine in the GS-GOGAT cycle, converting inorganic $\mathrm{N}$ into organic $\mathrm{N}$ in plants [10].

Plants actively take up $\mathrm{NO}_{3}{ }^{-}$from soil thanks to the activity of root specific transporters via a proton/nitratecoupled mechanism [11]. $\mathrm{NO}_{3}{ }^{-}$uptake transporters are classified in two categories: Low Affinity Transport System (LATS) and High affinity Transport System (HATS)
[12]. It was observed in Arabidopsis that LATS is mainly involved in transport at high nitrate concentrations, while HATS is active at low nitrate conditions $(<1 \mathrm{mM})$ $[13,14]$.

Chenopodium quinoa (Chenopodiaceae) seeds have a high protein content and a complete amino acid composition. Additionally, because of its wide adaptability and ability to grow under unfavorable environmental conditions, quinoa has been declared of global importance for food sustainability by the Food and Agricultural Organization [15].

Quinoa was domesticated approximately in 3000 B.C., probably on the high plateaus of the Altiplano of Peru and Bolivia [16]. Quinoa was spread out by the Inca Empire along the whole Andean mountain range, from Colombia to Southern Chile [17]. Today, there are more than 6000 landraces of Quinoa cultivated by farmers worldwide.

The Altiplano and Lowlands are representative geographical areas where Quinoa plants are submitted to contrasting environmental conditions in Chile. The Altiplano is immersed in the Atacama Desert in northern Chile. Quinoa plants growing in the Altiplano are exposed to extreme stressful climatic conditions called "cold desert". These conditions include high-flux solar radiation, very strong diurnal changes of temperature, limited volume of annual rainfall $(150-300 \mathrm{~mm} /$ year) and saline soils [18]. On the other hand, quinoa Lowland ecotypes (from central and southern Chile) have to deal with acidic and impoverished soils, elevated temperatures during growth and rainfall ranges from 500 to $1500 \mathrm{~mm} /$ year [19]. Both places and their edaphoclimatic conditions are representative of the wide stressful conditions (that reduce the probability of nutrient uptake and assimilation) Quinoa must cope with in Chile.

We hypothesize that ecotypes of Quinoa from Altiplano (landrace Socaire) and from Lowland (landrace 
Faro) have developed differential adaptive responses in order to survive under conditions of low availability of $\mathrm{N}$ in the different climatic zones. In this regard, we wanted to elucidate whether the contrasting landraces of Quinoa store different level of $\mathrm{N}$ metabolites on seeds that could determine a differential speed of germination and competitiveness for nutrients. Thus, we determined the Nrelated metabolite composition of seeds and their germinative capacity. Further, seedlings of both landraces were grown at either sufficient nitrate $(\mathrm{HN})$ or low nitrate (LN) supply for 20 days, and several parameters were determined in order to elucidate the mechanisms of $\mathrm{N}$ uptake and assimilation at limiting $\mathrm{N}$ conditions during establishment of each quinoa landrace. These parameters included morphometrical measures, photosynthetic performance, protein storage, as well as activities and gene expression of $\mathrm{N}$-assimilating enzymes (NR, GS). A phylogenetic analysis of quinoa LATS and HATS homologues was performed, and relative quantification of expression of a selected LATS gene (a NPF6.3-like homologue) and a selected HATS gene (a NRT2.1-like homologue) were also performed. We found evidence for a differential performance regarding $\mathrm{N}$ uptake between landraces.

\section{Results}

\section{Seed germination, nitrogen content and metabolomic profiling}

Both Socaire and Faro had similar seed weights and N content (Fig. 1a and b). Even though both landraces reached 100\% germination after $48 \mathrm{~h}$ of imbibition (Fig. 1c). Socaire seeds displayed a significanty higher germination rate than that observed in Faro (3.5 versus 2.3 germinated seeds/h; Fig. 1d). Socaire reached an earlier total germination at $16 \mathrm{~h}$, versus $24 \mathrm{~h}$ in the case of Faro seeds (Suppl. Fig. S1).

A seed metabolite profile, comparing Socaire and Faro landraces, was performed. A total of 161 named metabolites were confirmed using an untargeted global metabolomic platform that combined Gas Chromatography Mass spectrometry (GC - MS) and Ultra performance Liquid Chromatography - Tandem Mass Spectrometer (UPLC/ MS/ MS) analyses of seeds from both landraces. The results revealed significant differences in metabolite content between landraces, which reflect the variations in seed origin and/or genetic background (Fig. 1e).

The confirmed 161 metabolites covered most of the primary metabolism and some of the secondary metabolism pathways. Metabolites were categorized into eight major metabolite groups including $\mathrm{C}$ - and $\mathrm{N}$-related pathways: sugars, sugars alcohols, fatty acids, TCA cycle, free aminoacids, purine and pirimidin metabolism, ornithine cycle and shikimic acid route (Figs. 1, 2 and 3e).
Similar levels of the most significant fraction of watersoluble carbohydrates and glycolytic intermediates including sucrose, raffinose, glucose-6-phosphate, glucose-1phosphate fructose-6-phosphate, 3-phosphoglyceraldehyde, phosphoenolpyruvate and pyruvate were found when comparing both landraces (Figs. 2 and 3). However, Socaire seeds had higher amounts of glucose, fructose and other more complex sugars (such as lyxose, arabinose, galactose and maltose) in comparison to Faro seeds.

Faro seeds had higher contents of sugar acids, sugar alcohols and ketose sugars, including galactonic acid (sugar acid), mio-inositol, ribitol, lyxitol, arabitol and erythritol. In addition, Faro seeds presented higher levels of fatty acids (including stearic acid, pelargonic acid, pantothenic acid, palmitic acid, oleic acid, octadecanol, myristic acid, linolenic acid, linoleic acid, arachidic acid, 1-monoolein, 2-monoolein and 1-monopalmitin), in comparison to Socaire seeds (Fig. 2). Regarding metabolites involved in the TCA cycle, Socaire seeds had higher amounts of all organic acids detected (citric acid, fumaric acid, isocitric acid, maleic acid, malic acid and alpha-ketoglutarate) (Fig. 2).

Socaire seeds also had higher levels of free N-related metabolites (non-associated to macromolecules) in comparison to Faro seeds (Fig. 3). Socaire seeds presented higher amounts of metabolites related to the purineand pyrimidine pathway (including: xanthosine, adenine, adenosine-5-monophosphate and ribose-5P; Fig. 3). Aditionally, significantly higher amounts of amino acids (aspartic acid, glutamine, histidine, proline and serine), including non-proteinic amino acids (hydroxynorvaline and nicotianamine), and dipeptides (cysteine-glycine and alanine-alanine) were found in Socaire seeds. The only exception was tryptophan, which was present in higher amounts in Faro than in Socaire seeds.

Regarding the ornithine pathway, Socaire seeds presented higher amounts of ornithine, citruline and the polyamine spermidine (Fig. 3). Concerning the shikimate pathway, Socaire seeds had higher amounts of shikimic acid, p-cumaric acid (4-hydroxycinnamic acid), caffeic acid (3,4-dihydroxycinnamic acid) and ferulic acid than Faro seeds.

\section{Effect of nitrate supply on growth and physiological parameters of Socaire and Faro seedlings}

Aditionally to the seed study in both landraces, we evaluated the performance of plants under different $\mathrm{NO}_{3}{ }^{-}$ supply conditions. To determine sufficient and limiting $\mathrm{NO}_{3}{ }^{-}$concentrations, we studied growth of both plant ecoytpes at different $\mathrm{N}$ concentrations. It was observed that $\mathrm{NO}_{3}{ }^{-}$supply had significant effects on plant growth (Suppl. Fig. S2a). Shoot fresh weight and leaf area increased with increased $\mathrm{NO}_{3}{ }^{-}$supply, up to reach maximum values when growing in presence of $20 \mathrm{mM} \mathrm{NO}_{3}{ }^{-}$ 


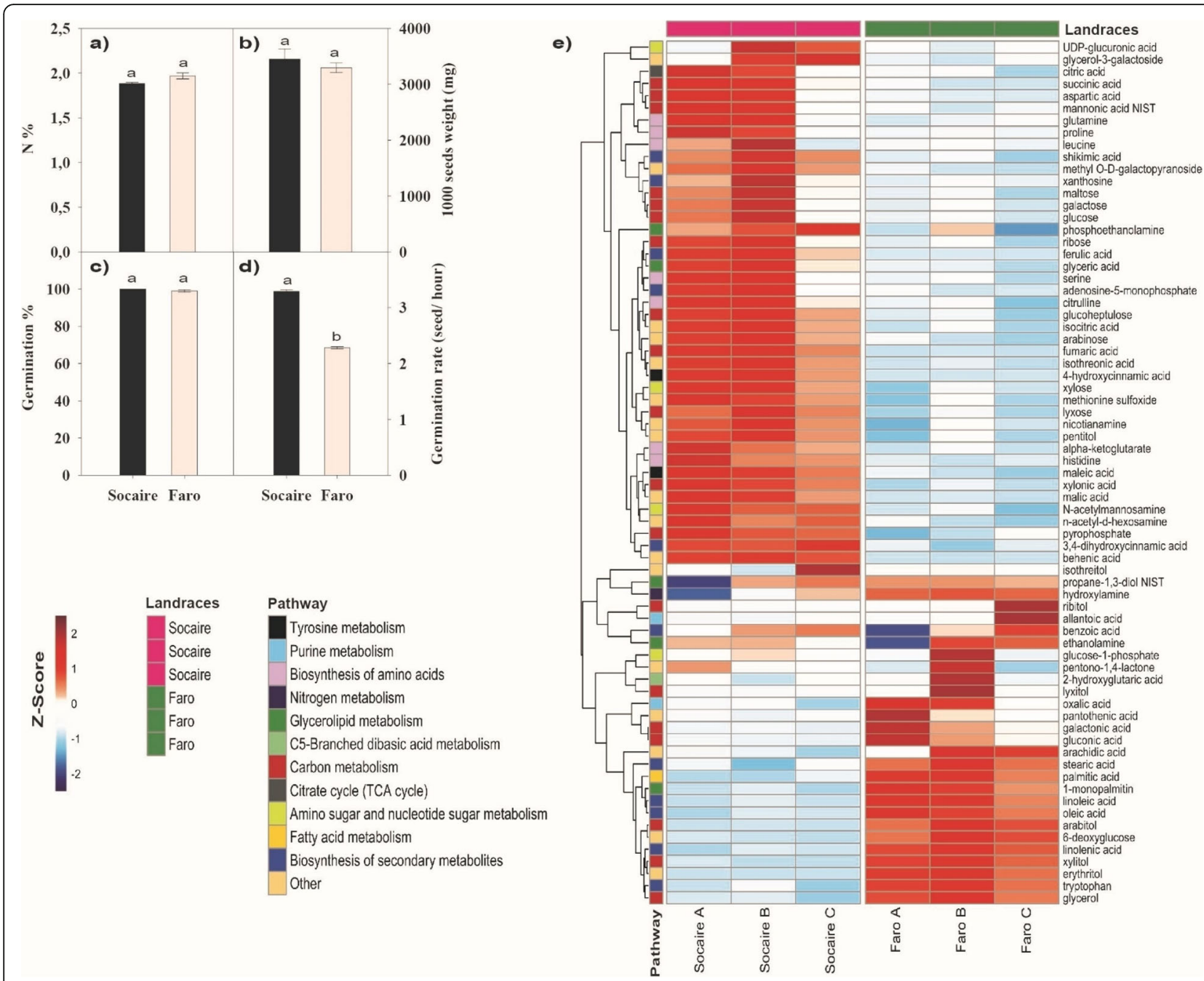

Fig. 1 Seed-related parameters in two landraces (Socaire and Faro) of Quinoa. (a) seed N content, (b) weight of 1000 seeds (c) percentage of germination and $\mathbf{d}$ ) germination rate were determined in seeds of each landrace. Bars show mean values $\pm \operatorname{SE}(n=5)$. Different letters represent significant differences among landraces and treatments at $P<0.05$ using two-way ANOVA. e) Heat map of selected metabolites with pathway information from KEGG. Only metabolites with low variance between replicates are showed. Normalized abundances of metabolites were scaled by Z-score and represented by a color scale. Letters after landrace $(\mathbf{a}, \mathbf{b}, \mathbf{c})$ indicate different samples $(50 \mathrm{mg})$ from three different plants $(n=3)$. Original full data set of all metabolites abundances are shown in Suppl. Table S1

and decreased at $100 \mathrm{mM}$ (Suppl. Fig. S2). Leaf area and shoot weight were significantly lower, between 0 and $5 \mathrm{mM}$ $\mathrm{NO}_{3}{ }^{-}$. Plant irrigation with $0.5 \mathrm{mM} \mathrm{NO}_{3}{ }^{-}$resulted in $80 \%$ less shoot weight and leaf area in both landraces compared to $20 \mathrm{mM} \mathrm{NO}_{3}{ }^{-}$. Therefore, $20 \mathrm{mM}$ and $0.5 \mathrm{mM} \mathrm{NO}_{3}{ }^{-}$ were chosen as high nitrogen $(\mathrm{HN})$ and low nitrogen (LN) supply treatment for subsequent experiments, respectively.

Seedlings of both landraces were grown for 24 days at HN or LN conditions. Although no significant differences in root length between both quinoa landraces in presence of $\mathrm{HN}$ and LN supply were observed (Fig. 4), the number of secondary roots and total root length were significantly higher in Socaire plants than in Faro plants at LN supply (Fig. 4c and d). Socaire plants displayed a significantly higher root/ shoot ratio than Faro plants at LN supply (Table 1).
Comparative leaf and root protein concentration, chlorophyll content and fluorescence, nitrate reductase (NR) and glutamine synthetase (GS) enzymatic activities, and their expression levels (CqNR and $C q G L N)$ were determined in both quinoa landraces growing at $\mathrm{HN}$ and LN supply. Changes in these parameters were calculated as the ratio of each value at low nitrogen supply (LN) to its value at HN conditions (LN vs $\mathrm{HN}$ ) for both landraces in a radar chart (Fig. 5).

At LN supply, a significant decrease in leaf protein concentration was observed in Faro but not in Socaire plants (Fig. 5). Nitrogen supply had not significant effect on root protein concentration in any of both quinoa landraces (Fig. 5). 

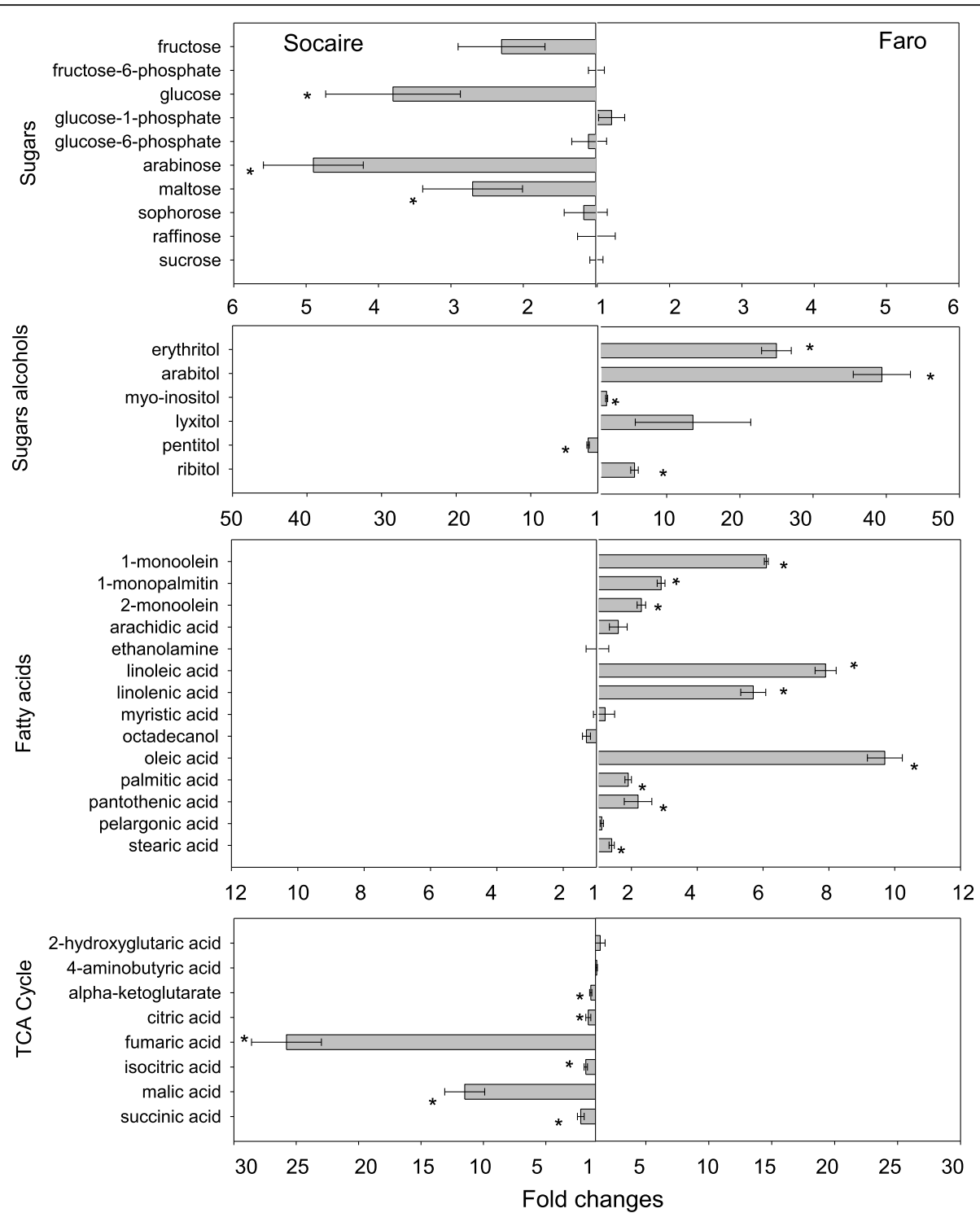

Fig. 2 C-related metabolites in seeds of two landraces of C. quinoa. Value bars facing the left of each section indicate the relative fold changes content of Socaire seed compared to Faro. Value bars facing the right of each section indicate relative increased content in Faro seeds compared to Socaire. Values are representative of mean \pm SE of three independent pool of seeds. Asterisks show significant differences between treatments or landraces using one-way ANOVA followed by Fisher LSD test; $P<0.05$

Both quinoa landraces showed a decrease of about $70 \%$ in chlorophylls content when growing at LN supply (Fig. 5); thus, the Chla/Chl $b$ ratio is maintained in spite of $\mathrm{N}$ supply treatment. No differences in this response were found among landraces.

Fluorescence parameters of chlorophyll a were quantified in order to understand the effect of $\mathrm{N}$ supply on the photosynthetic apparatus. $\mathrm{Fv} / \mathrm{Fm}$ is an indicator of stress in plants, and it represents the maximum quantum efficiency of Photosystem II. No significant differences in $\mathrm{Fv} / \mathrm{Fm}$ values were found when comparing both landraces, and nitrate supply had not a significant effect on this parameter (Fig. 5).
The photochemical quenching $(\mathrm{qL})$ reflects the proportion of energy used on photochemical process, whilst the nonphotochemical quenching (NPQ) is an indicator of photoprotective mechanisms and its enhancement is related to thermal dissipation of excess of absorbed light energy. We found that, at LN conditions, both landraces were able to disipate the excess of energy as heat, but a decrease of $30 \%$ in the value of qL was observed in Faro plants, whilst no significant decrease was observed in Socaire plants (Fig. 5).

Nitrogen supply had a significant effect on NR and GS activities in both Socaire and Faro roots. Activities of both enzymes were significantly higher in LN than in $\mathrm{HN}$ conditions (Fig. 5). This response was 

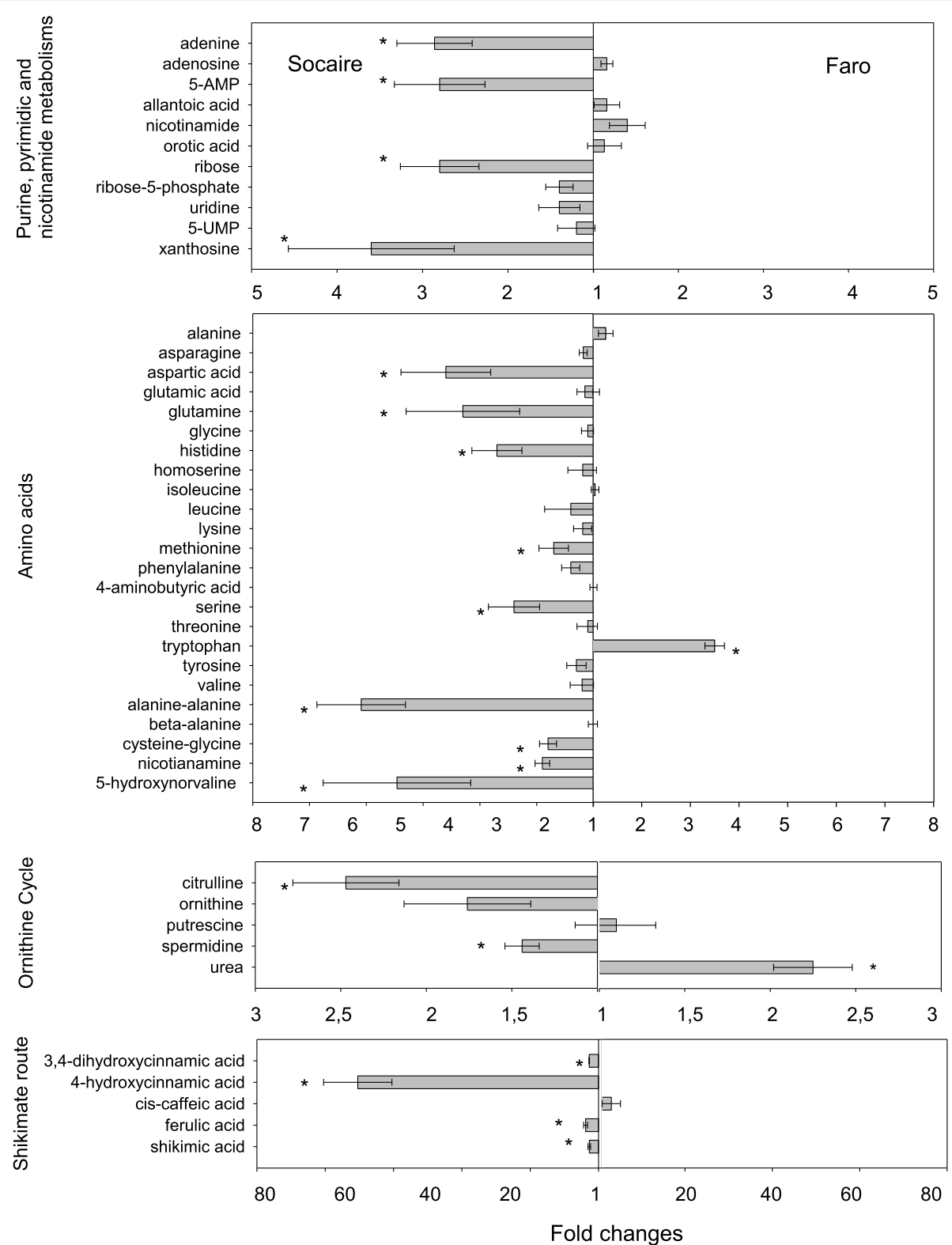

Fig. $3 \mathrm{~N}$-related metabolites in seeds of two C. quinoa landraces. Value bars facing the left of each section indicate the relative fold changes in content of these metabolites in Socaire seeds compared to Faro. Value bars facing the right of each section indicate relative increased content in Faro seeds compared to Socaire. Values are representative of mean \pm SE of three independent pool of seeds. Asterisks show significant differences between treatments or landraces using one-way ANOVA followed by Fisher LSD test; $P<0.05$

concomitant with an upregulation (of about 6-fold) of the CqNR gene in Socaire plants, but not in Faro, whose transcripts decreased to half. In the same way, only Socaire presented a significant increment on the CqGLN1 transcript, not observed in Faro plants.

\section{Phylogenetic analysis and gene expression of quinoa nitrate transporter homologues}

Phylogenetic analyses of some low-affinity nitrate transporters (NRT1/PTR Family, or NPF) and all high-affinity nitrate transporter (NRT2) homologues identified up to date in C. quinoa were performed (Fig. 6). In these analyses, nitrate transporter homologues from Arabidopsis thaliana and from two other plant species of the Chenopodioideae subfamily (Beta vulgaris and Spinacia oleracea) were also included.

Regarding LATS genes, several homologues of C. quinoa, S. oleracea and B. vulgaris clustered with A. thaliana NPF 6.3 genes (Fig. 6a). Other C. quinoa (but neither $S$. oleracea nor $B$. vulgaris) homologues clustered with NPF 6.2 and NPF 6.4 genes of A. thaliana, forming the respective clades (Fig. 5a). In each of these clusters, 

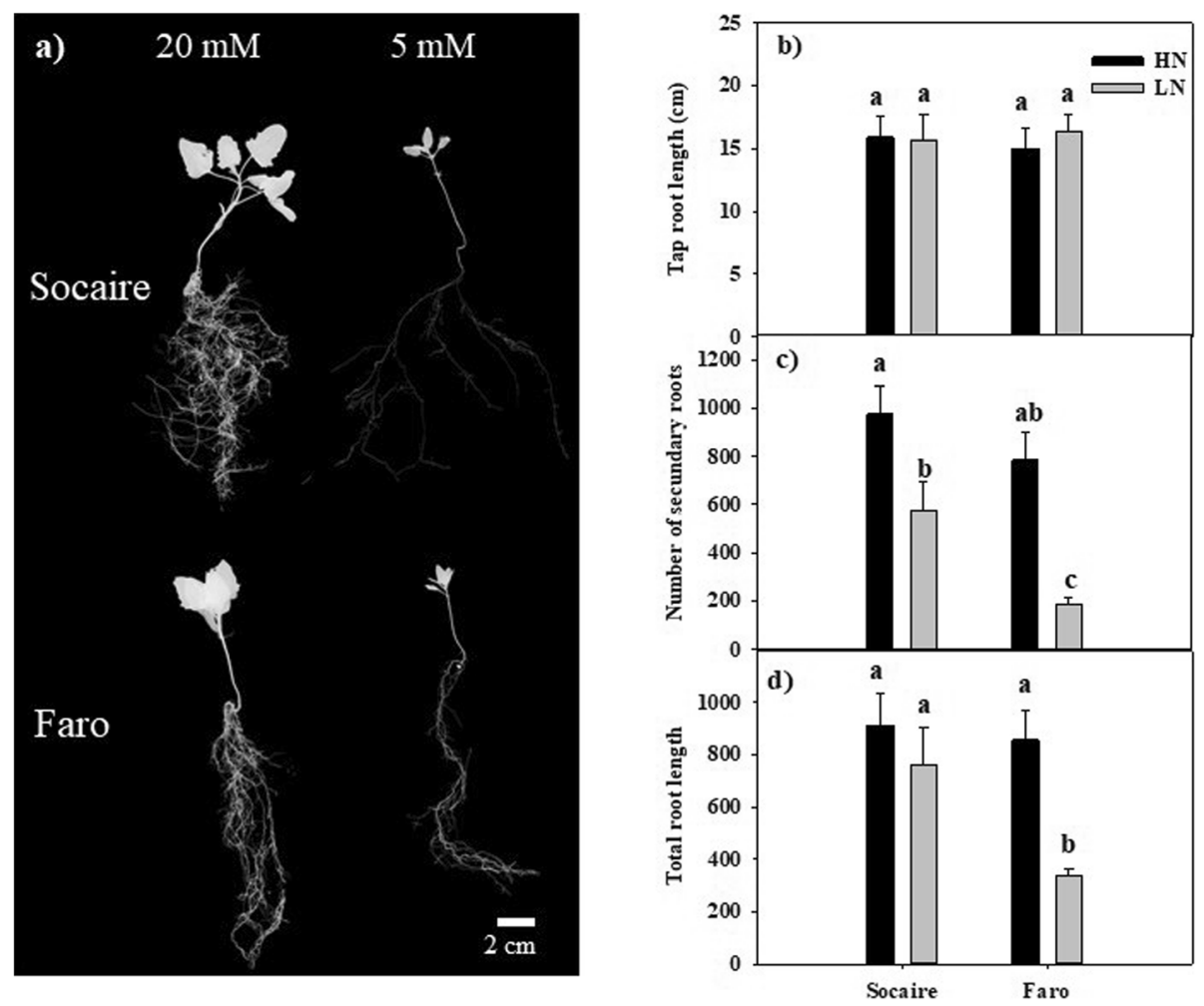

Fig. 4 The effect of $\mathrm{N}$ deficiency on root morphology in seedlings of C. quinoa. Images of plants subjected to $\mathrm{HN}\left(20 \mathrm{mM} \mathrm{NO}_{3}{ }^{-}\right)$and $\mathrm{LN}(0.5 \mathrm{mM}$ of $\mathrm{NO}_{3}{ }^{-}$) supplies for 24 days. (a) Tips root length, (b) Primary root length and (c) number of secondary roots. Values are mean $\pm \mathrm{SE}(n=7)$. Different letters show statistical differences using two-way ANOVA considering landraces and nutrition treatment (HN and LN) as factors (Fisher LSD test; $P<0.05)$

C. quinoa presented a higher number of homologues than the other species.

Regarding high-affinity transporters (HATS), several homologues of C. quinoa, S. oleracea and B. vulgaris clustered together with the A. thaliana NRT 2.5 gene (Fig. 6b). Several other homologues of the three species of the Chenopodioideae subfamily clustered with a clade containing A. thaliana NRT 2.1, NRT 2.2, NRT 2.3, NRT 2.4 and NRT 2.6 genes. No homologues to $A$. thaliana NRT 2.7 gene were found (Fig. 6b).
In order to perform gene expression studies of C. quinoa LATS and HATS homologues, transcriptional levels of NPF 6.3-like (Acc. No. XM_02191275) and HAT 2.1like (Acc. No. XM_021864786) gene homologues were analyzed by real-time PCR using gene-specific primers.

Transcriptional levels of the two nitrate transporter genes were detected in roots of Socaire and Faro plants. It was observed that nitrate supply had a significant effect on expression of these low-affinity and high-affinity nitrate transporters in quinoa. A significant upregulation

Table 1 Measures of leaf area and dry biomass in C. quinoa plants grown at two $\mathrm{NO}_{3}{ }^{-}$levels. Leaf area, root dry weight, shoot dry weight, shoot/root ratio and total biomass of plants grown at sufficient nitrate supply $\left(\mathrm{HN}, 20 \mathrm{mM} \mathrm{NO}_{3}^{-}\right)$and low nitrate supply $(\mathrm{LN}$, $0.5 \mathrm{mM}_{\text {of } \mathrm{NO}_{3}}{ }^{-}$) for 24 days. Values are means $\pm \mathrm{SE}(n=7)$. Different letters show statistical differences using two-way ANOVA considering landraces and nitrate treatment (HN and LN) as factors (Fisher LSD test; $P \leq 0.05$ )

\begin{tabular}{|c|c|c|c|c|}
\hline & \multicolumn{2}{|l|}{ Socaire } & \multicolumn{2}{|l|}{ Faro } \\
\hline & $\mathrm{HN}$ & $\mathrm{LN}$ & $\mathrm{HN}$ & LN \\
\hline Leaf area $\left(\mathrm{cm}^{2}\right)$ & $3.5 \pm 0.30(b)$ & $0.6 \pm 0.06(c)$ & $4.0 \pm 0.22$ (a) & $0.5 \pm 0.03$ (c) \\
\hline Root weight (mg) & $17.9 \pm 2.8(\mathrm{a})$ & $2.8 \pm 0.2(b)$ & $17.0 \pm 1.2$ (a) & $2.4 \pm 0.2(b)$ \\
\hline Shoot weight (mg) & $37.2 \pm 7.0$ (a) & $6.2 \pm 0.8(b)$ & $47.6 \pm 6.2$ (a) & $8.3 \pm 0.6(b)$ \\
\hline Shoot/root ratio & $2.4 \pm 0.6(a b)$ & $2.2 \pm 0.2(b)$ & $2.9 \pm 0.4(a b)$ & $3.4 \pm 0.2(\mathrm{a})$ \\
\hline Total biomass (mg) & $55.1 \pm 6.0$ (a) & $9.0 \pm 0.9(b)$ & $64.6 \pm 6.4$ (a) & $10.8 \pm 0.6(b)$ \\
\hline
\end{tabular}




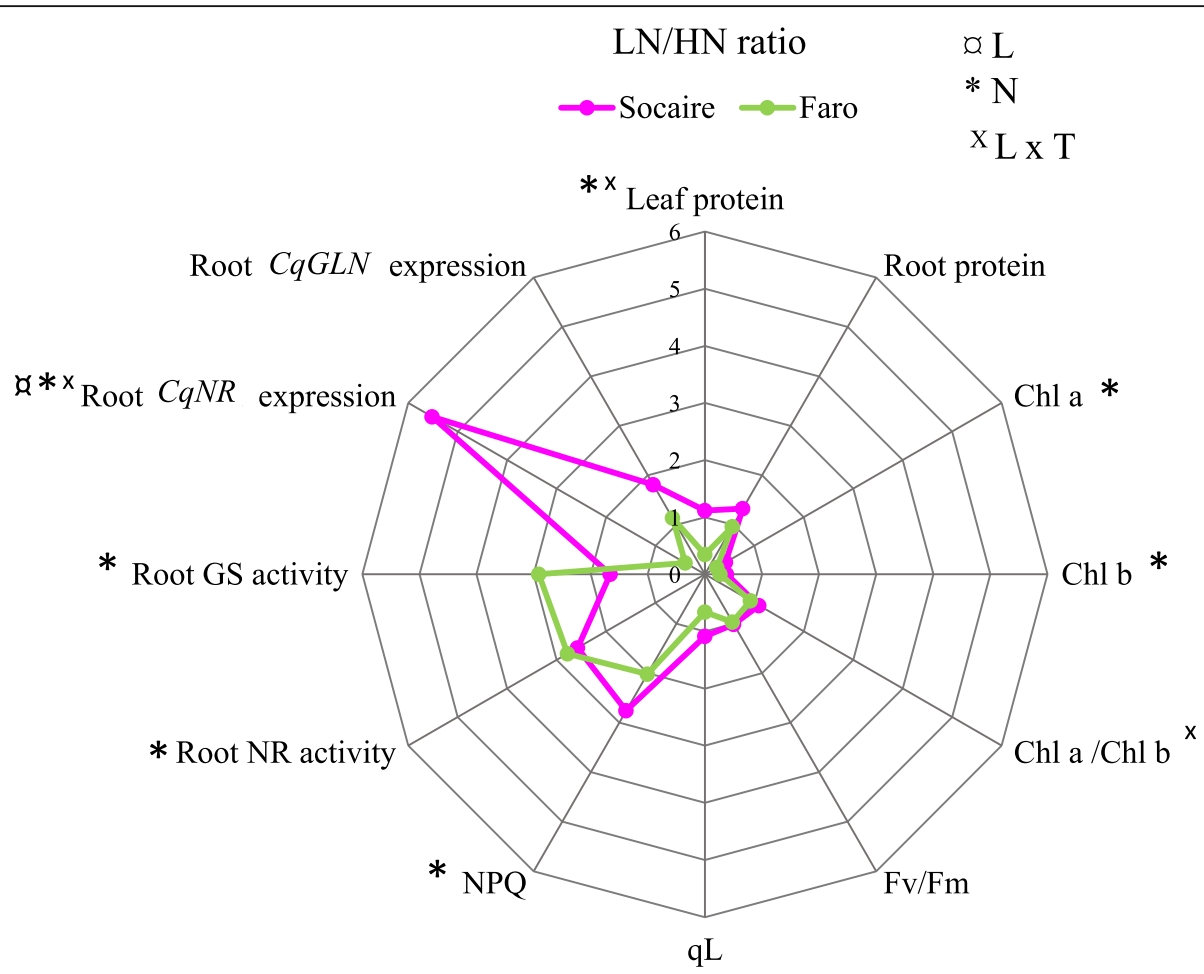

Fig. 5 Physiological parameter changes in response to $L N$ in Socaire and Faro. Radar chart shows relative changes in leaf and root proteins, chlorophylls (Chl $a$ and $b$ and Chl $a / b$ ratio), chlorophyll fluorescence parameters Fv/Fm (maximal efficiency of PSII), NPQ (non-photochemical quenching) and qL (the proportion QA in the reduced state), protein and NR and GS enzymatic activities and their respective gene expressions (CqNR and CqGLM) in two landraces of quinoa. Changes were calculated as the ratio of $\mathrm{LN}$ level $\left(0.5 \mathrm{mM} \mathrm{of} \mathrm{NO}_{3}^{-}\right)$to $\mathrm{HN}_{\text {level }}\left(20 \mathrm{mM} \mathrm{NO}_{3}{ }^{-}\right)$. Values are means $(n=5)$. Socaire ratio changes were denoted in pink color and Faro in green. Symbols ${ }^{*},{ }^{*}$ and ${ }^{x}$ indicate significant differences among landraces $(\mathrm{L})$, nitrogen treatments $(\mathrm{N})$ and interaction among both factors $(\mathrm{L} \times \mathrm{N})$ using two-way ANOVA (Fisher $L S D$ test; $P<0.05)$. Data for statistical analysis are shown in Suppl. Table S2

of the NPF 6.3-like homologue was observed in Socaire, but not in Faro plants, at LN supply (Fig. 7a). Additionally, a significant increase in mRNA levels of the HAT 2.1-like homologue was observed in both Socaire and Faro plants at LN supply, in comparison with transcript levels observed at HN supply (Fig. 7b).

\section{Discussion}

\section{Seed composition of landraces}

Influence of contrasting environments and genetic background on seed compounds of different quinoa landraces had been focused principally from a human nutritional perspective [20]. Notwithstanding, our metabolic seed characterization attempts to unveil the contrasting physiological performance of two landraces from the seed stage.

Typically, it was observed in ecological studies that total seed $\mathrm{N}$ concentration was an important factor for the release of dormancy $[5,6,8]$. Our results have shown that plants adapted to contrasting climatic conditions (Altiplano and Lowland) and local management procedures produced seed with similar weight and $\mathrm{N}$ content (Fig. 1), however presented differential rate of germination (Fig. 1d and Fig. S1). These results suggest that $\mathrm{N}$ content per se does not reflect the wide differences in $\mathrm{N}$ metabolites complexity, distribution, rate of use and fate during germination [8]. It was suggested that a higher free-metabolite content could favor the rate of water imbibition and could have a role as a fast fuel of energy in the early phase of germination $[5,6]$. This is consistent with our results, in which Socaire, the landrace with higher storage of free metabolites also displayed a faster germination (Figs. 1, 2 and 3). Our metabolomics analysis highlighted the large metabolite differences between landraces from Altiplano and Lowland areas. The metabolites that exhibit highest range of values classified the landraces into two opposite sets, according to their level in seeds (Fig. 1e). These results are in accordance with those of Chen et al. [20], who classified the quinoa varieties into two groups regarding their bioactive phytochemicals.

It is interesting to note that Socaire seeds had higher levels of carbohydrates with higher calorific sugars, such as glucose and fructose, that can support the energetic cost for germination serving as carbon skeletons in the TCA cycle (malate, isocitric acid, succinic acid, 
(a)

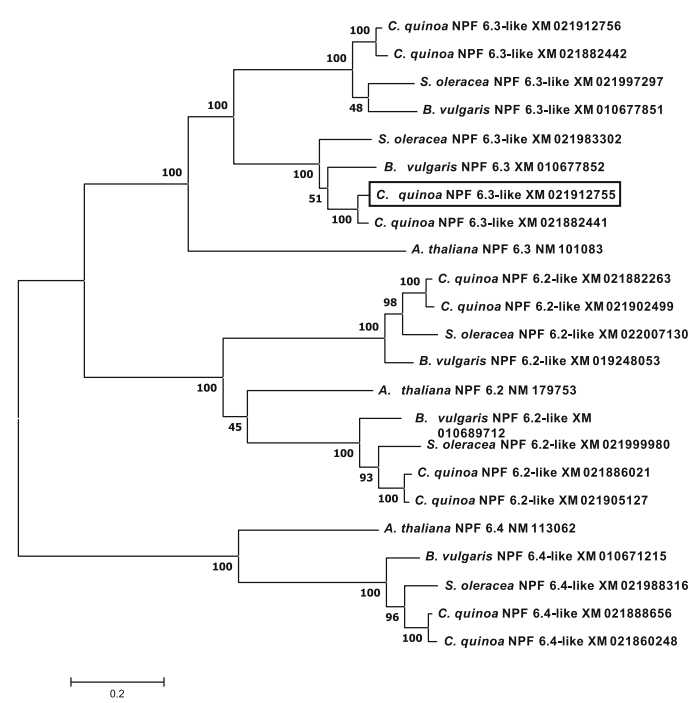

(b)

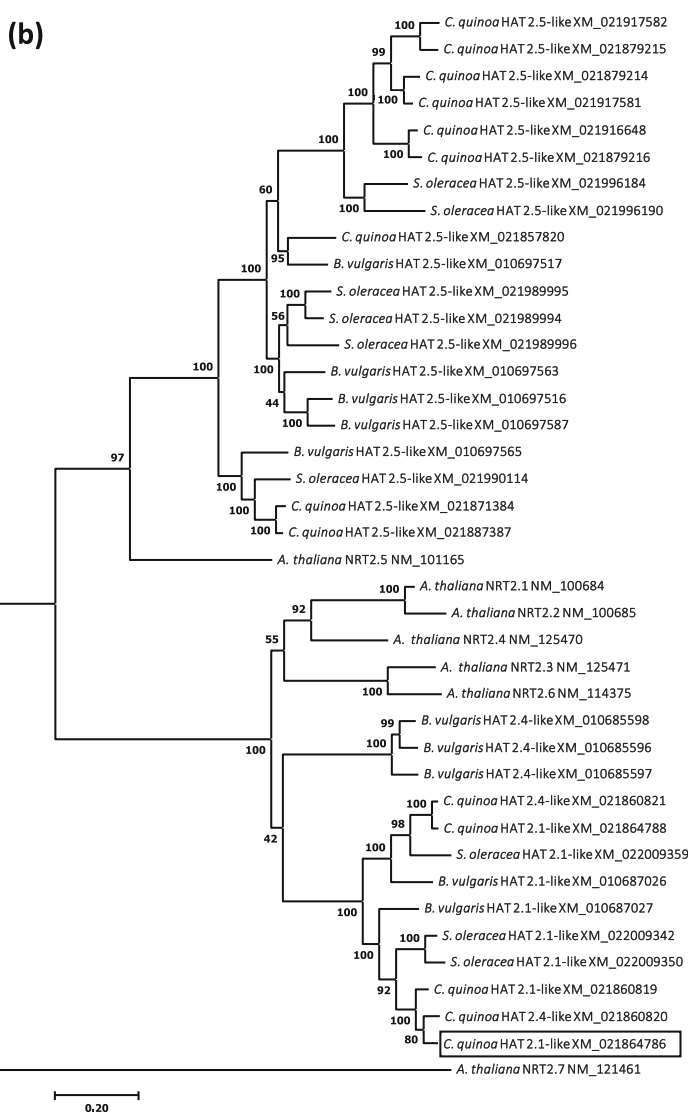

Fig. 6 Molecular phylogenetic analyses of low and high affinity nitrate transporters in C. quinoa. Phylogenetic optimal trees of nucleotide coding sequences of nitrate transporter homologues of C. quinoa, other two species of the Chenopodiaceae family (S. oleracea and B. vulgaris), and A. thaliana. The evolutionary history was inferred using the Maximum-Likelihood method based on the Tamura-Nei model. In the phylogenetic analysis of Low Affinity Transporter (LAT) homologues $(\mathbf{a})$, the tree with the highest log likelihood $(-21,210.48)$ is shown. In the phylogenetic analysis of high affinity transporters (HATs) (b) , the tree with the highest log likelihood $(-29,578.42)$ is shown. The percentage of trees in which the associated taxa clustered together is shown next to the branches. Initial tree(s) for the heuristic search were obtained automatically by applying Neighbor-Joining and BioNJ algorithms to a matrix of pairwise distances estimated using the Maximum Composite Likelihood (MCL) approach, and then selecting the topology with superior log likelihood value. A discrete Gamma distribution was used to model evolutionary rate differences among sites. The tree is drawn to scale, with branch lengths measured in the number of substitutions per site. The analysis involved 23 (a) and 40 (b) nucleotide sequences. All positions with less than 95\% site coverage were eliminated. Accession number for each sequence is indicated. Gene homologues characterized by gene expression in this study are contained in boxes. Evolutionary analyses were conducted in MEGA7

fumarate) [21]. On the other hand, Faro seeds stores higher amounts of alcohol sugars, considered "sweetener" with low caloric power $(0.4 \mathrm{kcal} / \mathrm{g})$ such as arabitol and erythritol. Furthermore, Faro seeds store higher amount of oleic acid, linolenic acid and linoleic acid (fatty acid metabolites) than Socaire seeds. Several studies in oilseed plants demonstrated that free fatty acids and glycerol improve oxidative stability of seed through conversion into sugars, supporting TCA cycle and improving seed germination and seedling establishment processes [22].

Another noteworthy fact is the higher content of Nrelated metabolites in Socaire than in Faro seeds. Among the processes involved in activation of seed metabolism upon imbibition, purine salvage pathway (and not "de novo" synthesis) has been the proposed as a route for purine nucleotide synthesis, because of their favorable energetic reactions with lower ATP cost [23]. Purine pathway-related metabolites including AMP, UMP, xanthosine and aspartate (among others), were present in higher amounts in Socaire than in Faro seeds (Fig. 3). It is suggested that the higher content of purine-related metabolites, ribose 5-P and TCA intermediates observed in Socaire, could be contributing to the different enzymatic reactions related with the main pathways associated with energy production and nucleic acid biosynthesis after during seed germination [23, 24].

The aromatic amino acids tryptophan, phenylalanine and tyrosine are precursors for a wide range of secondary metabolites that are important for plant growth as 


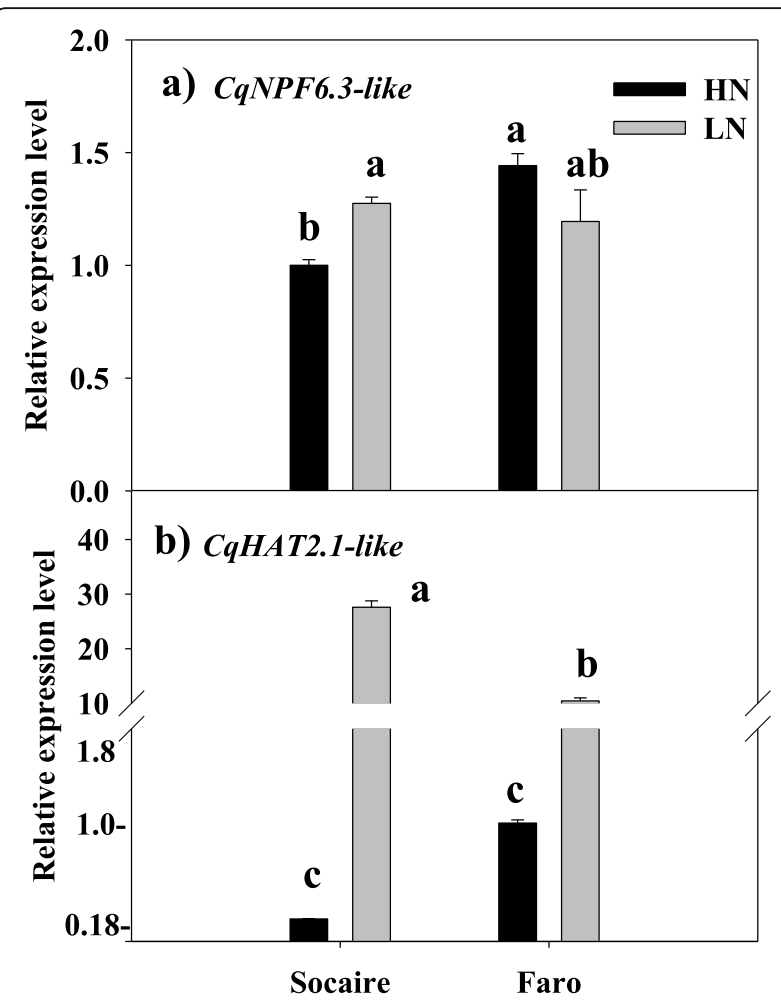

Fig. 7 Relative expression levels of low and high affinity nitrate transporters in root of $C$. quinoa plants grown at two levels of nitrate. Relative transcript levels of low (NPF6.3-like) (a) and high (HATS 2.1-like, (b) affinity nitrate transporters in roots of two landraces of $\mathrm{C}$. quinoa seedlings grown at $\mathrm{HN}\left(20 \mathrm{mM} \mathrm{NO}_{3}{ }^{-}\right)$and $\mathrm{LN}$ ( $0.5 \mathrm{mM}$ of $\mathrm{NO}_{3}{ }^{-}$) for 24 days. Total RNA prepared from root tissues was analyzed by quantitative real-time PCR analysis. The constitutively expressed EF1-a gene was used as endogenous control in order to normalize experimental results. Mean values \pm SE $(n=3)$ are represented. Different letters show statistical differences using two-way ANOVA considering landraces and nitrate supply conditions as factors (Fisher LSD test; $P<0.05$ )

well as for human nutrition and health. The occurrence of higher levels of shikimic acid, caffeic acid (3,4-dihydroxycinnamic acid), p-cumaric acid (4-hydroxycinnamic acid) and ferulic acid in Socaire seeds suggests an upregulation of secondary metabolism in this landrace in comparison with that of Faro seeds. It was reported that variations on these metabolites in Amaranthus seeds could be due to different climatic conditions of the provenances, but also to their genetic background [25]. Interestingly, tryptophan was the only amino acid present in higher amount in Faro than in Socaire seeds and, in agreement with our data, this amino acid is a retarder of germination in wheat [26].

Other important amino acids that were enhanced in Socaire compared to Faro seeds were glutamine and proline (Fig. 3). Both amino acids are involved in the ornithine cycle and polyamine pathway. Additionally, citrulline and spermidine levels were 2-fold higher in
Socaire than in Faro seeds. All these high nitrogen content compounds were related to drought and salinity tolerance in quinoa [27, 28].

Certainly, these differential levels of metabolites in the dry seed do not necessarily imply a direct effect on germination, but many works had suggested that the levels and proportions of some metabolites in the seed affect processes required for later germination or even establishment [29].

\section{Differences in seedlings performance were revealed at low $\mathrm{NO}_{3}{ }^{-}$supply}

In order to continue with studies of developmental processes, we were interested in understanding the early performance of these quinoa plants at sufficient $(\mathrm{HN})$ and low $\mathrm{NO}_{3}^{-}$(LN) supply conditions. Interestingly, when both landraces were grown at $\mathrm{HN}$ conditions, they presented similar responses in the parameters studied. However, at LN supply, differences in their physiological performances were revealed.

Both landraces produced similar total biomass at both nitrogen supply conditions 24 days after germination (Table 1), but the shoot: root ratio was significantly different between landraces at LN supply, indicating that Socaire allocated a higher proportion of resources in the root than Faro seedlings under those conditions. It is known that roots, and specifically root tips, are important sites where plant root absorbs water and nutrients [1]. Lateral roots proliferate preferentially in nutrientrich zones and are repressed at insufficient $\mathrm{N}$ supply [30]. Our results showed that, similarly to other species, LN supply induced a reduction in the number of lateral roots, compared to $\mathrm{HN}$ conditions, in C. quinoa. Nevertheless, Socaire displayed a higher number of lateral roots and higher total root length than Faro seedlings at LN supply (Fig. 4). Taking into account that it was observed a higher leaf protein concentration in Socaire than in Faro seedlings (Fig. 5), we suggest that maintenance of a higher number of lateral roots might be a crucial factor contributing to the higher $\mathrm{N}$ accumulation observed in Socaire ecotype.

It is known that the vast majority of $\mathrm{N}$ is stored principally in leaves as Rubisco and other proteins from the light harvesting complex in the thylakoid system of plants [1]. Observed decreases in the levels of chlorophylls in both landraces under LN conditions (Fig. 5) could be the result of adjustments of the photosynthetic apparatus to reduce the energy captured by plants to avoid photodamage. The ability for photosynthetic apparatus adjustment in quinoa is also supported by fluorescence chlorophyll $a$ analysis, in which similar levels of $\mathrm{Fv} / \mathrm{Fm}$ at $\mathrm{HN}$ and $\mathrm{LN}$ conditions are indicating that these plants did not suffer damage of PSII. Furthermore, due the changes in the photochemical ( $\mathrm{qL}$ ) and non- 
photochemical quenching (NPQ) at LN, regarding $\mathrm{HN}$ conditions, it is suggested that both landraces experienced dynamic regulations in the use of light, modifying the energy used on photochemical process and/or in the energy dissipated to the environment as heat. The major difference in these aboveground measured parameters between landraces was the capacity of Socaire plants to maintain $\mathrm{qL}$ values under $\mathrm{LN}$ conditions. Considering that photosynthesis is the principal process that explains qL values in Quinoa [28], this response could be the basis of the different amount of leaf protein between landraces under LN conditions.

It is known that LN supply (and other stress conditions) induces production of secondary metabolites, triggering protein degradation and increasing photorespiration [31]. All these processes induce a rise in cellular $\mathrm{NH}_{4}{ }^{+}$concentration, which is toxic and must be incorporated into amino acids in a reaction catalyzed by the GS enzyme. We suggest that the increment in GS activity in roots might be related to a maintenance of cellular homeostasis in the whole plant. GS activity changes in Socaire were related to up-regulation of CqGLN1; however, such relationship was not observed in Faro plants. It was suggested that transcriptional and also post-translational modifications could be involved in GS increased affinity and activity in different plant species [31, 32].

Nitrate reductase (NR) is the enzyme that catalyze the limiting reaction in the reduction of $\mathrm{NO}_{3}{ }^{-}$. It is known that NR activity is dependent on $\mathrm{NO}_{3}{ }^{-}$supply; therefore, an increased activity of this enzyme at LN conditions was an unexpected observation (Fig. 5). A plausible explanation of this result is that NR in roots is modulated in a different way than in shoots, so root NR could be activated at minor $\mathrm{NO}_{3}{ }^{-}$concentrations [33]. This could be an explanation in Socaire plants, but not in Faro plants, which NR transcript levels dropped by half (Suppl. Table S2). Further studies are necessary in order to understand the biochemical and molecular regulation of key enzymes of root $\mathrm{N}$ physiology in this species.

\section{Phylogenetic and gene expression studies of $\mathrm{NO}_{3}{ }^{-}$ transporters in quinoa}

Four gene families of transporters are involved in nitrate uptake in plants. They include the NPF (NITRATE TRANSPORTER 1/PEPTIDE TRANSPORTER FAMI LY) transporters (low affinity nitrate transporter system or LATS) and the NRT2 (NITRATE TRANSPORTER 2) family (high affinity nitrate transporter system or HATS) [12]. We have characterized, by phylogenetic analysis, different LATS and HATS gene homologues in quinoa and two other plant species from the Chenopodioideae subfamily (Spinacia oleracea and Beta vulgaris; Fig. 6).
NPF family includes a large number of genes (up to 53 members in A. thaliana). Arabidopsis NPF6.3 (NTR1.1/ CHL1) was the first nitrate transporter identified. This gene is expressed in several root tissues, where this transporter performs nitrate uptake from soil [13]. NPF6.3 (NTR1.1/CHL1) was firstly identified as low affinity nitrate transporter but, later on, it was observed that this transporter can sense the external nitrate concentration and alter their transport activity. Thus, this protein has been proposed as transceptor with $\mathrm{N}$ sensing function [14]. NPF6.3 can switch to high-affinity activity in LN conditions, and an increase in NPF6.3 mRNA transcripts in presence of low levels of $\mathrm{NO}_{3}{ }^{-}$was observed $[11,13]$. In fact, knockout NPF6.3 mutants are defective in high affinity $\mathrm{NO}_{3}{ }^{-}$uptake [34]. We identified up to four homologues of NPF6.3 in quinoa (Fig. 6a). The presence of these homologues probably results from gene duplication events and suggests a fine-tuning regulation of root $\mathrm{N}$ uptake by the members of this gene clade in quinoa. We have studied the expression of one of these NPF6.3 homologues (NPF6.3-like, Acc. no. XM 021912755) in roots of Socaire and Faro landraces submitted to either HN or LN supply (Fig. 7a). At HN conditions, gene expression of NPF6.3-like is significantly higher in Faro plants than in Socaire plants, suggesting a role of this gene in low-affinity $\mathrm{NO}_{3}{ }^{-}$uptake, and a putative higher activity and/or efficiency for $\mathrm{NO}_{3}{ }^{-}$uptake in Faro plants. However, this gene is significantly upregulated in Socaire plants at LN supply, suggesting a high affinity $\mathrm{NO}_{3}{ }^{-}$transport function for this gene in this landrace (Fig. 7a). In Arabidopsis, phosphorylation of a Thr residue in LN conditions promotes NPF6.3 high affinity $\mathrm{NO}_{3}{ }^{-}$transport [13]. Interestingly, all four NPF6.3 homolog sequences identified in quinoa have conserved the corresponding Thr residue. It is also interesting to note that two NPF6.3 homologues identified in spinach (Fig. 6a) are mainly expressed in roots, they are upregulated at $\mathrm{HN}$ conditions, and both homologues presented different expression patterns when comparing low $\mathrm{N}$ and high $\mathrm{N}$ plant varieties [35]. Thus, functional characterization studies must be performed in order to elucidate the functional roles of these transporter homologues in C. quinoa and in other plants of the Chenopodioideae subfamily.

Regarding HATS, seven NRT2 genes were identified and characterized in Arabidopsis, and it is known that the NRT2 family plays and important role in nitrate acquisition from soil under $\mathrm{N}$ limitation conditions [14]. It was observed that the constitutive gene NRT2.5 of $A$. thaliana plays a role in root nitrate influx [36]. It is interesting to note that plants from the Chenopodioideae subfamily have several (up to 9 , in the case of C. quinoa) homologues that cluster together with this nitrate transporter of Arabidopsis (Fig. 6b), suggesting an important 
role of these genes in root nitrate uptake in C. quinoa and the other plants of the Chenopodioideae subfamily. These homologues are probably the result of gene duplication events.

By another way, A. thaliana NRT2.1 is the most studied transporter of the NRT2 family, and it was characterized as the main component of the HATS for nitrate root uptake under most conditions. This gene displays a very strict tissue-specific transcriptional profile, confined to the outer layers of the root tissues, and knockout mutation of this gene results in the loss of up to $75 \%$ of the root nitrate influx $[36,37]$. Plants of the Chenopodioideae subfamily have no close orthologues for NRT2.1, but they have several homologues that cluster together with a clade containing several inducible HATS expressed in roots of $A$. thaliana (that is, NRT2.1, NRT2.2 and NRT2.4) and other two homologues (NRT2.3 and NRT2.6) whose function in plants is little known [12]. We have studied the expression of one of these HATS homologues (High Affinity Transporter 2.1like, Acc. no. XM_021864786) in roots of Socaire and Faro plants submitted to either HN or LN supply (Fig. $7 \mathrm{~b})$. This gene is significantly induced in both quinoa landraces at LN supply. This result agrees with the expression patterns of its homologues in A. thaliana roots, which display a transient upregulation by $\mathrm{N}$ starvation [12]. In the case of quinoa, this upregulation was significantly higher in Socaire than in Faro plants, suggesting a putative higher activity and/or efficiency for nitrate uptake at LN supply in Socaire plants. Interestingly, it was reported that expression of a $S$. oleracea NRT2.1-like homologue (Acc. no. XM_022009342) is higher in roots of a low-nitrate content variety than in roots of a high $\mathrm{NO}_{3}{ }^{-}$content variety, suggesting a role in $\mathrm{NO}_{3}{ }^{-}$uptake; however, no gene upregulation was observed in LN supply conditions [35], suggesting that the role and regulation of this homologue could be different in different plant species of the Chenopodioideae subfamily. It was reported that $A$. thaliana NRT2.1 can be involved in lateral root development [36]; concordantly, we observed that Socaire plants display a higher number of lateral roots, and higher total root length, than Faro plants at LN supply (Fig. 4c, d).

No homologues of the tonoplast-specific NRT2.7 gene of A. thaliana were found in Chenopodioideae. This gene is important for nitrate accumulation in seeds of $A$. thaliana $[12,38]$. Future studies must elucidate whether these plants of the Chenopodioideae subfamily have nitrate transporter homologues with specific functions in seeds.

Additional studies must be performed in order to elucidate expression patterns, substrate specificity and functional roles of LATS and HATS homologues of quinoa. These studies will allow a characterization of the contribution of these genes to nitrate accumulation and to identify which homologues are more important in order to cope with infertile soils.

\section{Conclusions}

In conclusion, our results suggest that Socaire and Faro landraces have different strategies to cope with low nutrient acquisition. Socaire seeds were able to germinate faster than Faro, which could be associated to a different metabolite composition of seeds. $\mathrm{NO}_{3}{ }^{-}$treatment affected the expression of related genes, modulating root morphology and aerial performance differentially among ecotypes. Considering variation on soil quality and $\mathrm{N}$ sources on the different places [39], specific adaptations to $\mathrm{NO}_{3}{ }^{-}$uptake between ecotypes could be shaping our results. Thus, our work opens new future questions: how different sources of $\mathrm{N}$ can influence their uptake and assimilation in a long widely expanded species as quinoa?

Our findings are important as exploration of different quinoa germplasm ecotypes with different sensitivity to $\mathrm{NO}_{3}{ }^{-}$limitation. The identification of valuable traits performed here could be used for screening and selecting $\mathrm{N}$ tolerant germplasm for their spread in poor soils.

\section{Methods}

\section{Seed collection}

Two landraces of Chenopodium quinoa were used in this work: Socaire from Altiplano (San Pedro de Atacama, Atacama Desert, Chile), and Faro from Central Chile. Socaire seeds were collected in a private field $\left(23^{\circ} 34^{\prime} \mathrm{S}\right.$ $67^{\circ} 54^{\prime} \mathrm{W}, 3500$ m.a.s.l.) with the permission of owner. Socaire community and CEAZA were in accordance to research Socaire quinoa germplasm according the agreement related to the project FIA PYT-2014-0280.

Faro seeds were collected in Vicuña City (in an experimental station of the Banco Base Inia Intihuasi (La Pepa, $30^{\circ} 2^{\prime} \mathrm{S} 70^{\circ} 42^{\prime} \mathrm{W}, 616$ m.a.s.l.) with all the permission required by the Institution (http://163.247.128.32/gringlo$\mathrm{bal} /$ search.aspx). Pedro Leon (Banco Base Inia Intihuasi) performed formal identification of the specimen plants. It is worth to note that $C$. quinoa is not endangered species, and experimental research was in according to the practices of SAG (Servicio Agricola y Ganadero) of Chile.

Seeds of both landraces were collected in summer (February) in each location. Total percent and available Nitrogen were $0.09 \%$ and $46 \mathrm{mg} / \mathrm{kg}$ in Socaire soils, and $0.12 \%$ and $42 \mathrm{mg} / \mathrm{kg}$ in Vicuna soils, respectively. Further characterization of agroecological conditions in both places are described in Garcia et al. and Montes et al. $[40,41]$. Collected seeds were stored in dry conditions at room temperature for 5 months, until experiments were performed. 


\section{Seed characterization and metabolite profiling}

Seeds from three randomly selected plants were collected separately for the different experiments (characterization, metabolomics profile and germination). For weight measurements, Socaire and Faro quinoa grains were dried in an oven at $80^{\circ} \mathrm{C}$ overnight, and 1000 -seed weight of each landrace was measured. One hundred milligram of grinding seeds was used to quantify $\mathrm{N}$ content by the method of Kjeldahl et al. [42].

For the metabolomic analysis, seeds were frozen, ground to powder and lyophilized to generate $50 \mathrm{mg}$ samples for each sample. Metabolite profiling and analysis was performed at the West Coast Metabolomics Center (UC Davis, Davis, CA, USA), according to the methodology described in Botanga et al. [43]. The homogenization, extraction and derivatization of the seed powder was according to Fiehn et al. [44]. Chromatography was performed following the protocol described in Botanga et al. [43]. Metabolites were identified using the Fiehnlib libraries [45]. Data were further processed using the algorithms implemented in the open-source BinBase metabolome database [46].

Raw data were normalized, filtered and analyzed using the MetaboAnalyst 3.0 webserver [47]. Heatmap plots (to visualize metabolites profiles) were performed using the pheatmap R package. Data were scaled by Z-sScore to capture metabolites with similar behavior. Clustering of metabolites was performed using the default pheatmap Ward method. Metabolites pathway information was obtained from KEGG API (https://www.kegg.jp/ kegg/rest/keggapi.html) using a Shell script.

\section{Germination}

Fifty seeds of three different individual of both landraces were used for each experiment. Seeds from both C. quinoa landraces were placed on Petri dishes with filter paper; sterile distilled water was added as needed to ensure adequate moisture for germination. Seeds were incubated for $48 \mathrm{~h}$ at $24{ }^{\circ} \mathrm{C}$ in the dark. The number of germinated seedlings was recorded every $4 \mathrm{~h}$ for $48 \mathrm{~h}$. This experiment was performed in triplicate. Germination was considered complete when the radicle emerged from the seed. Germination rate (number of germinated seeds/h) was recorded for seeds of each landrace during $48 \mathrm{~h} \mathrm{[48].} \mathrm{The} \mathrm{germination} \mathrm{percentage,}$ defined as [number of germinated seeds/number of total seeds] $\times 100$ [49] was also recorded every $4 \mathrm{~h}$ up to $48 \mathrm{~h}$ after seed imbibition.

\section{Determination of sufficient and low nitrate supply}

In order to determine the sufficient and limiting $\mathrm{NO}_{3}{ }^{-}$ supply concentrations for both Socaire and Faro plant landraces, germinated seeds presenting similar lengths of emerged radicle were transplanted into $700 \mathrm{~mL}$ pots containing sand:perlite (1:1). Seedlings were grown under growth chamber conditions $\left(21^{\circ} \mathrm{C}, 16 \mathrm{~h}\right.$ light $/ 8 \mathrm{~h}$ dark photoperiod, $57 \%$ relative humidity) for 20 days. Plants were watered with MS 407 nutrient medium, which contained the macro- and micronutrients described by Murashige and Skoog [50], except nitrate, potassium and phosphate. In order to compensate for the lack of those nutrients, nutrient solution was supplemented with $85 \mathrm{mg} / \mathrm{L} \mathrm{KH}_{2} \mathrm{PO}_{4}, 950 \mathrm{mg} / \mathrm{L} \mathrm{KCl}$, and different concentrations of $\mathrm{NO}_{3}{ }^{-}$as $\mathrm{KNO}_{3}$. Six nitrogen treatments $\left(0.0,0.5,2.0,5.0,20\right.$ and $\left.100 \mathrm{mM} \mathrm{NO}_{3}{ }^{-}\right)$were applied in order to determine sufficient and limiting nitrate supply conditions for both quinoa genotypes. Ten pots (with 3 plants each) were submitted to each nitrogen treatment.

Seedlings were irrigated with the different solutions at field capacity during the time of the experiment. Plants were also irrigated in order to compensate for water losses during the time of the experiment. At the end of the experiment, samples of whole plants were collected, and growth parameters were measured in order to evaluate sufficient and low nitrogen supply concentrations.

\section{Seedling performance at sufficient and low nitrate supply} In order to study the performance of both Quinoa landraces at sufficient and limiting $\mathrm{N}$ conditions during establishment, seedling of quinoa of both landraces were grown with irrigation at two $\mathrm{NO}_{3}{ }^{-}$concentrations, previously established with the experiment mentioned above (Section 2.4): $20 \mathrm{mM}$ and $0.5 \mathrm{mM} \mathrm{NO}_{3}{ }^{-}$, corresponding to sufficient $(\mathrm{HN})$ and low $(\mathrm{LN}) \mathrm{NO}_{3}{ }^{-}$supply, respectively. Thirty pots of $700 \mathrm{~mL}$ (3 plants per pot) were used for each $\mathrm{N}$ supply condition per landrace, using the same plant growth conditions described above (Section 2.4). The experiment was run for 24 days in a completely randomized design, that included additional plants grown in order to prevent bordering effect. At the end of the experiment, plants with at least four true leaves were collected.

For the study of the mechanisms involved in $\mathrm{N}$ uptake and assimilation, Chlorophyll a fluorescence, biomass, chlorophylls and protein content, NR and GS enzymatic activities and gene expression, and nitrate transporter gene expression were quantified in plants of both landraces submitted to both $\mathrm{N}$ treatments.

\section{Plant morphometric analyses}

Leaf area $(n=5$ plants of each landrace submitted to each treatment) was measured through image analysis using the Image software. Dry weights of leaves, shoots and roots $(n=5$ plants of each landrace submitted to each treatment) were determined by drying the tissues at $60^{\circ} \mathrm{C}$ for $48 \mathrm{~h}$ till constant weight. Number of secondary roots and total root length $(n=5$ plants of each 
landrace submitted to each treatment) were determined by image analysis using the WinRhizo software [51].

\section{Protein content quantification}

Leaves and roots ( $n=5$ plants of each landrace submitted to each treatment) were ground in liquid nitrogen and homogenized in $400 \mu \mathrm{L}$ of extraction buffer $(50 \mathrm{mM}$ Tris- $\mathrm{HCl} \mathrm{pH} 7.8,1 \mathrm{mM}$ EDTA, $1 \mathrm{mM}$ DTT, $10 \mathrm{mM}$ $\mathrm{MgSO}_{4}, 5 \mathrm{mM}$ sodium glutamate, $10 \%$ ethylene glycol). After centrifugation $(10,000 \mathrm{~g}$ for $10 \mathrm{~min})$, the supernatant was used to measure total protein content by the Bradford assay [52]. Bovine serum albumin was used as standard.

\section{Chlorophyll quantification and chlorophyll fluorescence measurements}

Chlorophyll $a$ and $b$ contents were determined spectrophotometrically following the method described by Lichtenthaler and Buschmann [53].

Chlorophyll (Chl) fluorescence measurements were performed $(\mathrm{n}=5$ plants of each landrace submitted to each treatment) using a portable fluorometer (FMS 2, Hansatech Instruments Ltd., Norfolk, UK). Leaves were dark-adapted for $20 \mathrm{~min}$ prior to measurements. Measurements were performed at chamber temperature. Actinic light used was of $300 \mu \mathrm{mol}$ photons $\mathrm{m}^{-2} \mathrm{~s}^{-1}$, as described in Bascuñán-Godoy et al. [54]. Fluorescence parameters were calculated as described in Maxwell and Johnson and Kramer et al. [55, 56].

\section{Nitrate reductase and glutamine synthetase activities of roots}

Both nitrate reductase (NR; EC 1.6.6.1) and glutamine synthetase (GS; EC 6.3.1.2) enzymes catalyze the limiting steps in the reduction of $\mathrm{NO}_{3}{ }^{-}$to $\mathrm{NH}_{4}{ }^{+}$(primary assimilation), and the incorporation of $\mathrm{NH}_{4}{ }^{+}$into amino acids, respectively. NR activity was measured in roots $(n=5$ plants of each landrace submitted to each treatment) according to Kaiser and Lewis [57]. Total protein was extracted as described above, and the reaction was started by addition of $150 \mu \mathrm{L}$ of reaction buffer $(50 \mathrm{mM}$ $\mathrm{KH}_{2} \mathrm{PO}_{4}-\mathrm{KOH}$ buffer, $\mathrm{pH} 7.5 ; 10 \mathrm{mM} \mathrm{KNO}$ and $0.1 \mathrm{mM}$ $\mathrm{NADH})$ to $100 \mu \mathrm{L}$ of soluble protein extract. Samples were incubated at $30^{\circ} \mathrm{C}$ for $15 \mathrm{~min}$. The NADH oxidation was measured by spectrophotometrical methods at $340 \mathrm{~nm}$. GS activity was measured in roots $(n=5$ plants of each landrace submitted to each treatment) by the formation of $\gamma$-glutamyl hydroxamate using the method described by O'Neal and Joy [58]. In order to perform the enzymatic reaction, $400 \mu \mathrm{L}$ of protein extract were mixed with $150 \mu \mathrm{L}$ of reaction buffer $(100 \mathrm{mM}$ Tris- $\mathrm{HCl}$, $\mathrm{pH} 7.8 ; 50 \mathrm{mM}$ sodium glutamate, $5 \mathrm{mM}$ hydroxylamine hydrochloride, $50 \mathrm{mM} \mathrm{MgSO}$ and $20 \mathrm{mM} \mathrm{ATP}$ ) and incubated at $30^{\circ} \mathrm{C}$ for $20 \mathrm{~min}$. The reaction was stopped with detection solution $\left(0.37 \mathrm{M} \mathrm{FeCl}_{3}, 0.67 \mathrm{M} \mathrm{HCl}\right.$ and $20 \%$ trichloroacetic acid). Glutamyl hydroxamate was measured spectrophotometrically at $540 \mathrm{~nm}$ using $\gamma$ glutamyl hydroxamate as a standard.

\section{Phylogenetic analysis of nitrate transporters}

Nitrate transporter (LATS and HATS) homolog sequences of $C$. quinoa and two other species from the Chenopodioideae subfamily (Beta vulgaris and Spinacia oleracea) were obtained from the Phytozome (https:// phytozome.jgi.doe.gov/pz/portal.html) and NCBI (https://www.ncbi.nlm.nih.gov) databases, using the BLAST algorithm and the Arabidopsis thaliana homologues as query. The evolutionary history of these genes was inferred using the Maximum-Likelihood method based on the Tamura-Nei model [59]. Node robustness was assessed by the bootstrap method ( $\mathrm{N}=1000$ pseudoreplicates). Phylogenetic analyses were performed with MEGA7 [60]. After a first characterization by phylogenetic analysis, a LATS and a HATS homologue of quinoa were selected for gene expression studies.

\section{RNA extraction, first strand CDNA synthesis and quantitative real-time PCR}

Total RNA was isolated from quinoa roots using RNeasy Plant Mini kit (Qiagen). The RNA obtained was treated with RNase-free DNase I (Qiagen) and quantified with a NanoDrop 1000 spectrophotometer (Thermo Scientific, USA). RNA intactness was verified by visual inspection of integrity of $28 \mathrm{~S}$ and $18 \mathrm{~S}$ rRNA bands in denaturing formaldehyde/agarose gel electrophoresis. RNA was stored at $-80^{\circ} \mathrm{C}$ for further use.

RNA $(1 \mu \mathrm{g})$ was reverse-transcribed into singlestranded cDNA templates using the PrimeScript ${ }^{\mathrm{Tm}} \mathrm{RT}$ reagent Kit (Takara) and oligo-p $(\mathrm{dT})_{15}$ primer. Reverse transcription was done in equiproportions (i.e., from equal quantity of RNA) within all compared samples from each experiment. The cDNA synthesis reaction mixture was diluted 10-fold in distilled water before using in real-time PCR.

Gene-specific primers for real-time PCR reactions were designed using Primer 3 input software v. 0.4.0 (http://bioinfo.ut.ee/primer3-0.4.0/primer3/input.htm), to have melting temperatures of $58-60{ }^{\circ} \mathrm{C}$ and generate PCR products of $50-200 \mathrm{bp}$. The elongation factor (EF1alpha) was used as endogenous (housekeeping) gene in order to normalize experimental results [26]. Primer sequences and the accession numbers of the corresponding genes are as follows: EF1-alpha (forward, 5' - GTAC GCATGGGTGCTTGACAAACTC-3'; reverse, 5' TCAGCCTGGGAGGTACCAGTAAT-3'; GenBank accession no. XM_021860126); Nitrate reductase [NADH]like (forward, 5' -AGGACTGGACCATTGAGGTG-3', reverse 5'- GCTGCAGAACCCCAATTAAA-3'; Acc. 
no. XM_021892662.1); Glutamine synthetase cytosolic isozyme 1-1-like (forward 5' - AAAGGATATTTCGAGG ACAGGAGG-3', reverse 5' - CTTGAGAGACAGCT GCAGATT-3'); Acc. no. XM_021911887.1; NRT1/PTR Family (that is, NPF) 6.3-like (a LATS homologue) (forward, 5'-GAGACATGGCTAGCTGAGGA-3'; reverse, 5' -CCTTTTAGGCATGACATTAGCTACT-3'; Acc. no. XM_021912755); High-affinity Nitrate Transporter (that is, HATS) 2.1-like (forward, 5'-ATGTTGCTGA GTACGACGAC-3'; reverse, 5' - GGGACGTTGT GTAGGGGTAG-3'; Acc. no. XM_021864786).

Each PCR reaction contained $10 \mu \mathrm{L}$ of $2 \mathrm{X}$ SYBR Green PCR master mix (Agilent Technologies), 50 ng of cDNA, and $0.45 \mu \mathrm{M}$ (final concentration) of each primer, in a final volume of $20 \mu \mathrm{L}$. Real-time PCR reactions were run in an Agilent Mx3000P QPCR System (Agilent Technologies). The initial denaturing time was $3 \mathrm{~min}$ at $95^{\circ} \mathrm{C}$, followed by 35 PCR cycles consisting of $95^{\circ} \mathrm{C}$ for $30 \mathrm{~s}$ and $60^{\circ} \mathrm{C}$ for $20 \mathrm{~s}$. After the PCR cycles, the purity of the PCR products was checked by analysis of the corresponding melting curve. The comparative $2^{(-\Delta \Delta C T)}$ method was used to quantify the relative abundance of transcripts [61]. Experiments included three biological replicates, and three technical replicates for each biological replicate were performed.

\section{Statistical analyses}

Data were analyzed with the STATISTICA v6.0 software package (Statsoft Inc., Tulsa, OK, USA, www.statsoft. com). One-way ANOVA was used to identify differences between landraces during germination.

To analyze metabolite profiles and compare both landraces, first an exploratory data analysis was developed using principal components analysis (PCA) by means of scatterplot3d R package (Suppl. Fig. S3). PCA analysis revealed that the first principal component (PC1) explains $94 \%$ of the variance while PC2 and PC3 account for 4 and 1\%, respectively, grouping the data in two main clusters that correspond to Socaire and Faro landraces. Thus, the variation in the PCA components was most likely attributable to variance between landraces while smaller variations in $\mathrm{PC} 2$ and $\mathrm{PC} 3$ were attributable to differences between replicates.

From the 371 metabolites detected, only 161 with KEGG compound identity were analyzed (Suppl. Table S1). To compare metabolites with pathway information the 100 metabolites with the lowest variance between replicates from each landrace were selected and those without KEGG pathway information assigned were removed (Suppl. Table S1). Thus, 85 remnant metabolites were analyzed by a heat-map, including metabolite clustering analysis with pathway information from KEGG.

For the determination of sufficient and low nitrate supply, we used two-way ANOVA (level of significance
$P<0.05)$. Data from effects of nitrate supply on the different quinoa landraces (Socaire and Faro) were analyzed by two-way ANOVA. Fisher test was used to identify means with significant differences (level of significance $P<0.05)$.

\section{Supplementary information}

Supplementary information accompanies this paper at https://doi.org/10. 1186/s12870-020-02542-w.

\begin{abstract}
Additional file 1: Figure S1. Seed germination rate in Socaire and Faro landraces. Measurements were performed every $4 \mathrm{~h}$ during $24 \mathrm{~h}$ (50 seeds per plate, $n=3$ ). Asterisks indicate significant differences between landraces.

Additional file 2: Figure S2. Effect of $\mathrm{N}$ deficiency on growth parameters in $\mathrm{C}$. quinoa plants. Plants subjected to differing $\mathrm{NO}_{3}{ }_{3}^{-}$ supplies from 0 to $100 \mathrm{mM}$ per 20 days. (a) Images of seedlings after 20 days of treatment (b) Leaf area and (c) Shoot fresh weight. Values are means \pm SE $(n=7)$. Different letters show statistical differences using two-way ANOVA considering landraces and nutrition treatment $(20 \mathrm{mM}$ and $0.5 \mathrm{mM} \mathrm{NO}_{3}{ }^{-}$) as factors (Fisher LSD test; $P<0.05$ ).
\end{abstract}

Additional file 3: Figure S3: Principal component analysis (PCA) of metabolites from seeds of Socaire and Faro landraces.

Additional file 4: Table S1. Raw metabolomics data used for heatmap and metabolite clustering analysis.

Additional file 5: Table S2. Data of physiological. Biochemical and molecular parameters measured in Socaire and Faro quinoa plants submitted to $\mathrm{HN}\left(20 \mathrm{mM} \mathrm{NO}_{3}{ }^{-}\right)$and $\mathrm{LN}\left(0.5 \mathrm{mM}\right.$ of $\left.\mathrm{NO}_{3}{ }^{-}\right)$supply, and depicted in flow chart (Fig. 5). Values are mean $\pm \operatorname{SE}(n=5)$. Two-way ANOVA was used to denote significant differences considering landraces and nitrogen treatment as factors (Fisher LSD test; $P<0.05$ ). Significant $P$ values are in red.

\section{Abbreviations}

Chl: Chloropyll; Fv/Fm: Maximal efficiency of PSIl; GOGAT: Glutamine Oxoglutarate Aminotransferase; GS: Glutamine Synthetase; HATS: High Affinity Transport Systems; HN: Sufficient nitrate; KNO3: Saltpeter; LATS: Low Affinity Transport Systems; LN: Low nitrate; MCL: Maximum Composite Likelihood; N: Nitrogen; $\mathrm{NO}_{3}^{-}$: Nitrate; NiR: Nitrite Reductase; NPQ: Nonphotochemical quenching; NR: Nitrate Reductase; PSII: Photosystem II; qL: Photochemical quenching

\section{Acknowledgements}

We thank to the Banco de semillas INIA Intihuasi and Socaire Community by their generous contribution of seeds to this work.

\section{Authors' contributions}

$\mathrm{KP}, \mathrm{TC}, \mathrm{EOG}, \mathrm{Cl}, \mathrm{VB}, \mathrm{RA}, \mathrm{CS}, \mathrm{PC}$ and $\mathrm{LBG}$ designed the assays and wrote the article with contributions of all the authors. KP, CC and AV performed the assays, measurements and data analysis. LBG led the founding project. All authors read and approved the final manuscript.

\section{Funding}

This work was supported by Vicerrectoría de Investigación y Desarrollo de la Universidad de Concepción VRID-Iniciacion 218.111.065-1.OIN, PCI-CONICYT REDI170289, CONICYT Chile (R16A10003) and FIA PYT-2014-0280. The funders had no role in study design, data collection and analysis, decision to publish, or preparation of the manuscript.

\section{Availability of data and materials}

All data generated during this study are included in this published article and its supplementary information files.

Ethics approval and consent to participate Not applicable. 


\section{Consent for publication}

Not applicable.

\section{Competing interests}

The authors declare that they have no conflict of interest.

\section{Author details}

'Centro de Estudios Avanzados en Zonas Áridas (CEAZA), 1710088 La Serena, Chile. ${ }^{2}$ Departamento de Biología, Universidad de La Serena, Av. Raúl Bitrán 1305, 1710088 La Serena, Chile. ${ }^{3}$ Departamento de Ingeniería en Alimentos, Universidad de La Serena, La Serena, Chile. ${ }^{4}$ Umeå Plant Science Centre, Department of Forest Genetics and Plant Physiology, Swedish University of Agricultural Sciences, SE901 83, Umeå, Sweden. ${ }^{5}$ Escuela de Tecnología Médica, Facultad de Salud, Sede La Serena, Universidad Santo Tomás, La Serena1710172Chile. 'Laboratorio de Fisiología Vegetal, Departamento de Botánica, Facultad de Ciencias Naturales y Oceanográficas, Universidad de Concepción, Casilla 160-C, 4070386 Concepción, Chile. 'Departamento de Fisiología, Facultad de Ciencias Biológicas, Universidad de Concepción, 4070386 Concepción, Chile.

\section{Received: 27 January 2020 Accepted: 6 July 2020}

\section{Published online: 21 July 2020}

\section{References}

1. Marschner P. Marschner's Mineral Nutrition of Higher Plants. 3rd ed. London: Academic Press; 2012

2. Ezeagu IE, Petzke JK, Metges CC, Akinsoyinu AO, Ologhobo AD. Seed protein contents and nitrogen-to-protein conversion factors for some uncultivated tropical plant seeds. Food Chem. 2002;78:105-9.

3. Lieffering $M$, Andrews $M$, McKenzie BA. Nitrate stimulation of mobilization of seed reserves in temperate cereals: importance of water uptake. Ann Bot. 1996;78:695-701.

4. Grubb PJ, Metcalfe DJ, Grubb EAA, Jones GD. Nitrogen-richness and protection of seeds in Australian tropical rainforest: a test of plant defence theory. Oikos. 1998:82:467-82

5. Allen E, Moing A, Ebbels T, Maucourt M, Tomos A, Rolin D, et al. Correlation network analysis reveals a sequential reorganization of metabolic and transcriptional states during germination and gene-metabolite relationships in developing seedlings of Arabidopsis. BMC Syst Biol. 2010;4:62.

6. Ribeiro PR, Jan-Willems LA, Mudde E, Gonzaga-Fernandez L, Delmondez-De Castro R, Ligterink W, et al. Metabolite profiling of the oilseed crop Ricinus communis during early seed imbibition reveals a specific metabolic signature in response to temperature. Ind Crop Prod. 2015;67:305-9.

7. Hara Y, Toriyama K. Seed nitrogen accelerates the rates of germination, emergence, and establishment of rice plants. Soil Sci Plant Nutr. 1998;44: 359-66.

8. Soriano D, Huante P, Gamboa-de Buen A, Orozco-Segovia A. Seed reserve translocation and early seedling growth of eight tree species in a tropical deciduous forest in Mexico. Plant Ecol. 2013;214:1361-75.

9. Gojon A. Inorganic Nitrogen Acquisition and Signaling: Physiological and Molecular Aspects. In: Eshel A, Beeckman T, editors. Plant Roots: The Hidden Half. Boca Raton: CRC Press; 2013. p. 25. 1-25-18.

10. Wallsgrove RM, Turner JC, Hall NP, Kendall AC, Bright SW. Barley mutants lacking chloroplast glutamine synthetase-biochemical and genetic analysis. Plant Physiol. 1987:83:155-8.

11. Wang YY, Hsu PK, Tsay YF. Uptake, allocation and signaling of nitrate. Trends Plant Sci. 2012:17:458-67.

12. Krapp A, David LC, Chardin C, Girin T, Marmagne A, Leprince AS, et al. Nitrate transport and signalling in Arabidopsis. J Exp Bot. 2014;65:789-98.

13. Noguero M, Lacombe B. Transporters involved in root nitrate uptake and sensing by Arabidopsis. Front Plant Sci. 2016;7:1391.

14. Fan X, Naz M, Fan X, Xuan W, Miller AJ, Xu G. Plant nitrate transporters: from gene function to application. J Exp Bot. 2017;68:2463-75.

15. FAO The state of food insecurity in the world. Food and Agriculture Organization of the United Nations 2011. http://www.fao.org/docrep/014/ i2330e/i2330e.pdf. Accessed 20 Dec 2019.

16. Pearsall DM. Plant domestication and the shift to agriculture in the Andes. In: Silverman $\mathrm{H}$, Isbell W, editors. The handbook of south American archaeology. New York: Springer; 2008. p. 105-20.

17. Skarbø K. From lost crop to lucrative commodity: conservation implications of the quinoa renaissance. Hum Organ. 2015;74:86-99.
18. Reguera M, Conesa CM, Gil-Gómez A, Haros CM, Pérez-Casas MÁ, BrionesLabarca V, Bolaños L, Bonilla I, Álvarez R, Pinto K, Mujica Á, Bascuñán-Godoy $L$. The impact of different agroecological conditions on the nutritional composition of quinoa seeds. PeerJ. 2018:6:e4442.

19. Bascuñán-Godoy L, Sanhueza C, Pinto K, et al. Nitrogen physiology of contrasting genotypes of Chenopodium quinoa Willd. (Amaranthaceae). Sci Rep. 2018;8:17524.

20. Chen YS, Aluwi NA, Saunders SR, Ganjyal GM, Medina-Meza I. Metabolic fingerprinting unveils quinoa oil as a source of bioactive phytochemicals. Food Chem. 2019;286:592-9.

21. Fait A, Angelovici R, Less H, Ohad I, Urbanczyk-Wochniak E, Fernie AR, et al. Arabidopsis seed development and germination is associated with temporally distinct metabolic switches. Plant Physiol. 2006;142:839-54.

22. Ma Y, Zhang J, Li X, Zhang S, Lan H. Effects of environmental stress on seed germination and seedling growth of Salsola ferganica (Chenopodiaceae). Acta Ecol Sin. 2016;36:456-63.

23. Perl M. ATP synthesis and utilization in the early stage of seed germination in relation to seed dormancy and quality. Physiol Plant. 1986;66:177-82.

24. Witte CP, Herde M. Nucleotide metabolism in plants. Plant Physiol. 2020; 182(1):63-78.

25. Steffensen SK, Rinnan A, Mortensen AG, Laursen B, De Troiani RM, Noellemeyer EJ, et al. Variations in the polyphenol content of seeds of field grown Amaranthus genotypes. Food Chem. 2011;129:131-8.

26. Morris CF, Mueller DD, Faubion JM, Paulsen GM. Identification of Ltryptophan as an endogenous inhibitor of embryo germination in white wheat. Plant Physiol. 1988;88:435-40.

27. Ruiz KB, Rapparini F, Bertazza G, Silva H, Torrigiani P, Biondi S. Comparing salt-induced responses at the transcript level in a Salares and coastallowlands landrace of quinoa (Chenopodium quinoa Willd). Environ Exp Bot. 2017:139:127-42.

28. Bascuñán-Godoy L, Sanhueza C, Hernández CE, Cifuentes L, Pinto K, Álvarez $\mathrm{R}$, et al. Nitrogen supply affects photosynthesis and photoprotective attributes during drought-induced senescence in quinoa. Front Plant Sci. 2018;9:994.

29. Rosental L, Perelman A, Nevo N, Toubiana D, Samani T, Batushansky A, et al. Environmental and genetic effects on tomato seed metabolic balance and its association with germination vigor. BMC Genomics. 2016;17:1047.

30. Sun $\mathrm{CH}$, Yu JQ, Hu DG. Nitrate: a crucial signal during lateral roots development. Front Plant Sci. 2017:8:485.

31. Fuentes F, Bhargava A. Morphological analysis of quinoa germplasm grown under lowland desert conditions. J Agron Crop Sci. 2010;7:124-827.

32. Tabuchi M, Abiko T, Yamaya T. Assimilation of ammonium ions and reutilization of nitrogen in rice (Oryza sativa L.). J Exp Bot. 2007;58:2319-27.

33. Oaks A, Aslam M, Boesel I. Ammonium and amino acids as regulators of nitrate reductase in corn roots. Plant Physiol. 1977:59:391-4.

34. Sun J, Zheng N. Molecular mechanism underlying the plant NRT1.1 dualaffinity nitrate transporter. Front Physiol. 2015;6:386.

35. Wang X, Cai X, Xu C, Wang S, Dai S, Wang Q. Nitrate accumulation and expression patterns of genes involved in nitrate transport and assimilation in spinach. Molecules. 2018;23:2231

36. O'Brien JA, Vega A, Bouguyon E, Krouk G, Gojon A, Coruzzi G, et al. Nitrate transport, sensing, and responses in plants. Mol Plant. 2016;9:837-56.

37. Li W, Wang Y, Okamoto M, Crawford NM, Siddiqi MY, Glass A. Dissection of the AtNRT2.1:AtNRT2.2 inducible high-affinity nitrate transporter gene cluster. Plant Physiol. 2007:143:425-33.

38. Chopin F, Orsel M, Dorbe MF, Chardon F, Truong HN, Miller AJ, et al. The Arabidopsis ATNRT2.7 nitrate transporter controls nitrate content in seeds. Plant Cell. 2007:19:1590-602

39. Oyarzun CE, Godoy R, Leiva S. Atmospheric deposition of nitrogen in a transect from the Central Valley to cordillera de Los Andes. Rev Chil Hist Nat. 2002;75:233-43.

40. García M, Raes D, Jacobsen SE, Michel T. Agroclimatic constraints for rainfed agriculture in the Bolivian Altiplano. J Arid Environ. 2007;71:109-21.

41. Montes C, Rutllant JA, Aguirre A, Bascuñán-Godoy L, Juliá C. Terral de Vicuña, a foehnlike wind in semiarid northern Chile: meteorological aspects and implications for the fulfillment of chill requirements in deciduous fruit trees. J Appl Meteorol Climatol. 2016;55:1183-96.

42. Kjeldahl J. A new method for the determination of nitrogen in organic matter. Anal Chem. 1883;22:366-82.

43. Botanga CI, Bethke G, Chen Z, Gallie DR, Fiehn O, Glazebrook J. Metabolite profiling of Arabidopsis inoculated with Alternaria brassicicola reveals that 
ascorbate reduces disease severity. Mol Plant-Microbe Interact. 2012;25: 1628-38.

44. Fiehn O, Wohlgemuth G, Scholz M, Kind T, Lee DY, Lu Y, et al. Quality control for plant metabolomics: reporting MSI-compliant studies. Plant J. 2008;53:691-704.

45. Kind T, Wohlgemuth G, Lee DY, Lu Y, Palazoglu M, Shahbaz S, et al. FiehnLib: mass spectral and retention index libraries for metabolomics based on quadrupole and time-of-flight gas chromatography/mass spectrometry. Anal Chem. 2009;81:10038-48.

46. Fiehn O, Wolgemuth G, Scholz M. Setup and annotation of metabolomic experiments by integrating biological and mass spectrometric metadata. Proc Lect Notes Bioinf. 2005;3615:224-39.

47. Xia J, Sinelnikov IV, Han B, Wishart DS. MetaboAnalyst 3.0--making metabolomics more meaningful. Nucleic Acids Res. 2015;43:W251-7.

48. Ranal MA, Santana DG. How and why to measure the germination process? Braz J Bot. 2006;29:1-11.

49. Abiri R, Shaharuddin NA, Maziah M, ZNB Yusof1, Atabaki N, Sahebi M, et al. Quantitative assessment of indica rice germination to hydropriming, hormonal priming and polyethylene glycol priming. Chil J Agr Res. 2016;76: 392-400.

50. Murashige T, Skoog F. A revised medium for rapid growth and bio-assays with tobacco tissue cultures. Physiol Plant. 1962;15:473-97.

51. Arsenault IL, Poulcur S, Messier C, Guay R. WinRHIZO'm, a root-measuring system with a unique overlap correction method. HortScience. 1995;30: 906D-906.

52. Bradford MM. A rapid and sensitive method for the quantitation of microgram quantities of protein utilizing the principle of protein-dye binding. Anal Biochem. 1976;72:248-54.

53. Lichtenthaler HK, Buschmann C. Chlorophylls and carotenoids: measurement and characterization by UV-VIS spectroscopy. Curr Protoc Food Anal Chem. 2001;1:F4-3.

54. Bascuñán-Godoy L, Alcaíno C, Carvajal D. Different photoprotective responses under drought conditions of two predominant chilean swamp forest species. Gayana Bot. 2013;70:279-86.

55. Maxwell K, Johnson GN. Chlorophyll fluorescence-a practical guide. J Exp Bot. 2000;51:659-68.

56. Kramer DM, Johnson G, Kiirats O, Edwards GE. New fluorescence parameters for the determination of QA redox state and excitation energy fluxes. Photosynth Res. 2004;79:209.

57. Kaiser JJ, Lewis OAM. Nitrate reductase and glutamine synthetase activity in leaves and roots of nitrate-fed Helianthus annuus L. Plant Soil. 1984;77:12730.

58. O'Neal D, Joy KW. Glutamine synthetase of pea leaves. I. Purification, stabilization, and pH optima. Arch Biochem Biophys. 1973;159:113-22.

59. Tamura K, Nei M, Kumar S. Prospects for inferring very large phylogenies by using the neighbor-joining method. Proc Natl Acad Sci U S A. 2004;101: 11030-5.

60. Kumar S, Stecher G, Tamura K. MEGA7: molecular evolutionary genetics analysis version 7.0 for bigger datasets. Mol Biol Evol. 2016;33:1870-4.

61. Livak KJ, Schmittgen TD. Analysis of relative gene expression data using real-time quantitative PCR and the $2^{-\Delta \Delta C T}$ method. Methods. 2001;25:402-8.

\section{Publisher's Note}

Springer Nature remains neutral with regard to jurisdictional claims in published maps and institutional affiliations.

Ready to submit your research? Choose BMC and benefit from:

- fast, convenient online submission

- thorough peer review by experienced researchers in your field

- rapid publication on acceptance

- support for research data, including large and complex data types

- gold Open Access which fosters wider collaboration and increased citations

- maximum visibility for your research: over $100 \mathrm{M}$ website views per year

At BMC, research is always in progress.

Learn more biomedcentral.com/submissions 